\title{
A lay doctor's guide to the inflammatory process in the gastrointestinal tract
}

\author{
S Pathmakanthan, C J Hawkey
}

\section{Overview}

The immune system of the gastrointestinal tract represents the largest mass of lymphoid tissue in the body consisting of up to $10^{6}$ lymphocytes/g tissue. ${ }^{1}$ All appropriate and inappropriate inflammation in the gut is initiated by this gut associated lymphoid tissue (GALT). Several mediators of inflammation that include cytokines, chemokines, and eicosanoids help promote and regulate these functions but if unregulated can contribute to mucosal damage as seen in the inflammatory bowel diseases (IBDs). While the initiators of inflammation are variable in gastrointestinal disease, the pathways of immunologically mediated mucosal damage are common. The balance between proinflammatory cytokines and the production of anti-inflammatory molecules will determine the severity, extent, and outcome of mucosal inflammation.

During normal vaginal delivery, the gastrointestinal immune system is exposed to maternal enteric bacteria which rapidly colonise the infant's intestine reaching concentrations of $10^{11} / \mathrm{g}$ of stool. ${ }^{2}$ The continuous interaction between commensal bacteria present in the gastrointestinal tract and the immunological system create a steady state of "physiological inflammation" in the gastrointestinal mucosa. Physiological inflammation may become excessive though appropriate as part of a response to an invading pathogen in the case of salmonella, shigella, and Campylobacter enteritides or excessive and inappropriate as is the case with the IBDs. The extent of this abnormal immune response is likely to be both genetically and environmentally influenced. A number of inflammatory mediators are raised in IBD tissue and therapeutic intervention at this level is the basis of treatment.

Altered bacterial populations in the colon may be responsible for causing relapses of IBDs-for example, ulcerative colitis and Crohn's disease. This has raised the possibility of administering "probiotic" bacterial flora as a form of microbial interference treatment in order to disrupt the activity of an original bacterial insult. Bacterial preparations consisting of lactobacilli and bifidobacter have recently been shown to be effective in the excessive inflammation present in ileoanal pouchitis. ${ }^{3}$ Early indications also show that an oral preparation of a non-pathogenic Escherichia coli compares favourably with drug treatment, producing similar relapse rates and almost identical relapse-free intervals. ${ }^{4}$

\section{Anatomy}

Structurally, GALT (comprising the tonsils, adenoids, appendix, and the Peyer's patches ) is organised into different compartments. Aggregated follicles and Peyer's patches are distrib-
Division of Gastroenterology, University Hospital, Queens Medical Centre, Nottingham NG7 2UH, UK

$S$ Pathmakanthan C J Hawkey

Correspondence to: Dr Pathmakanthan (email: pcgshri@aol.com)

Submitted 5 August 1999 Accepted 13 January 2000

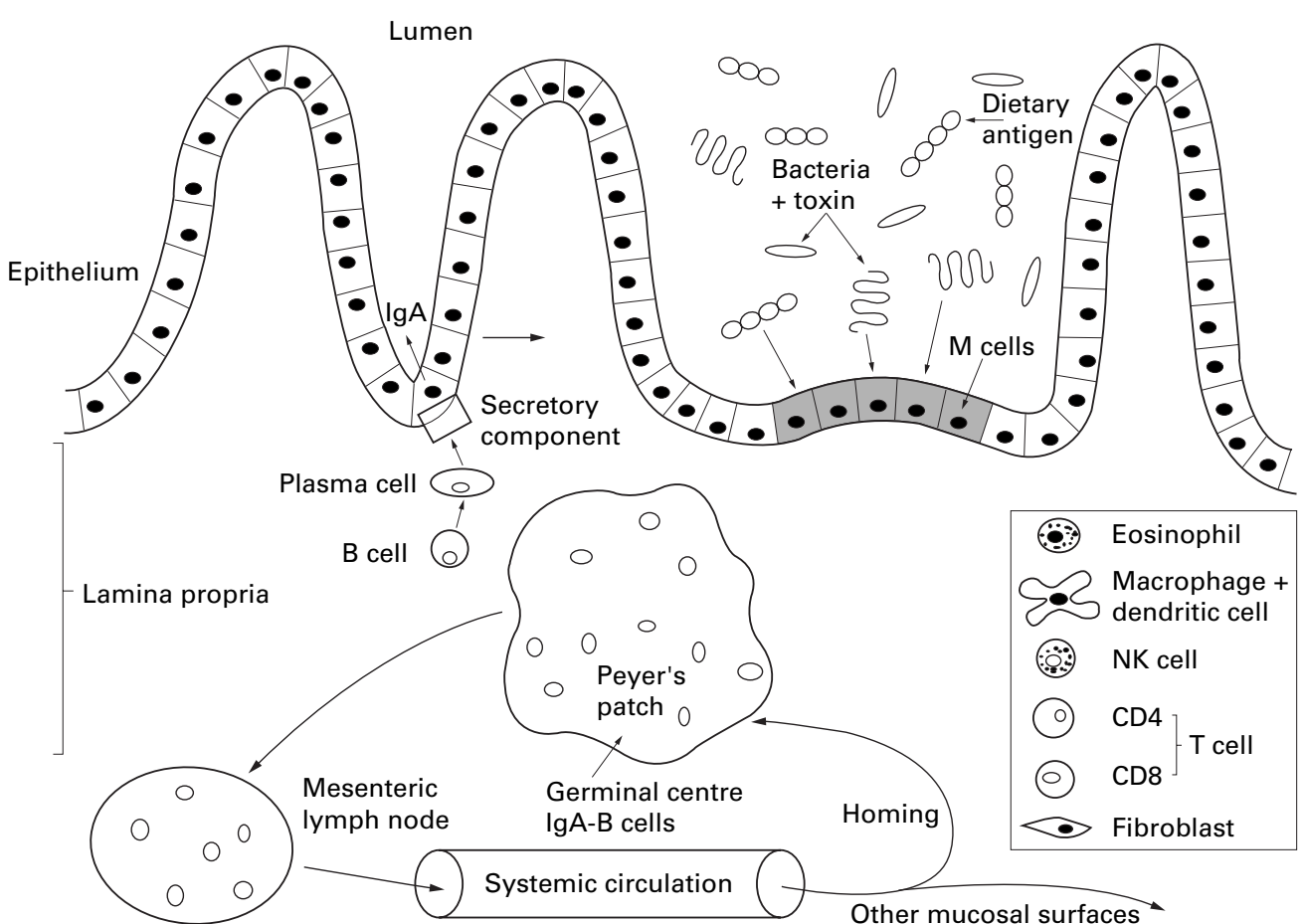

Figure 1 Diagrammatic representation of the major components of gastrointestinal inflammation and immunology (NK $=$ natural killer). 

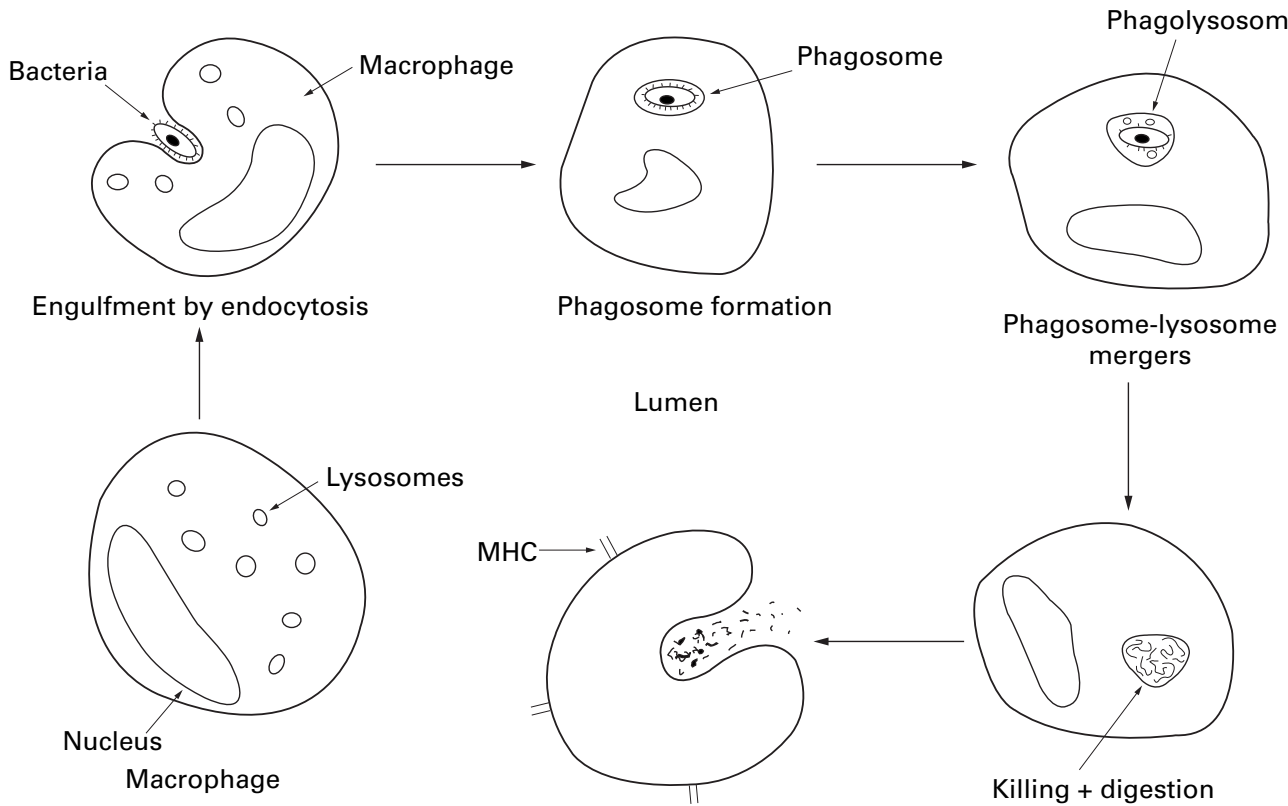

Phagosome formation

Phagosome-lysosome mergers

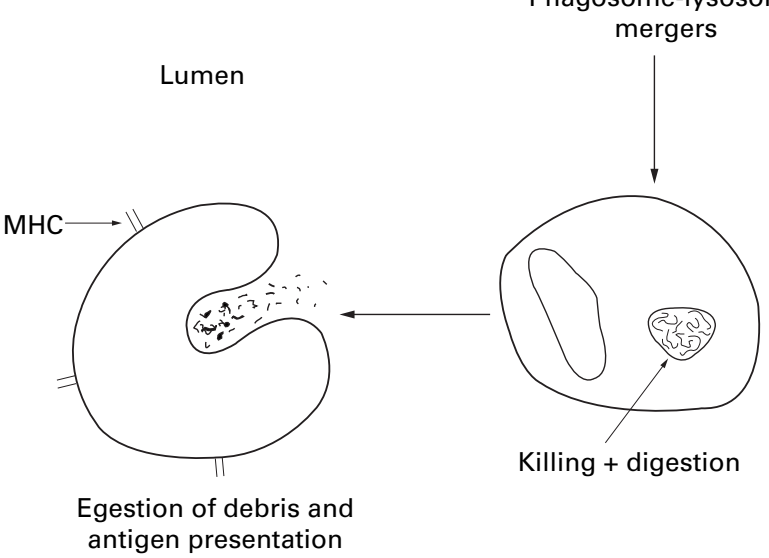

Figure 2 Role of macrophages in ingesting foreign protein and presenting antigen (MHC = major histocompatibility complex).

uted within the mucosa as diffuse lymphocyte populations (See fig 1). Lymphocytes are also present in the epithelial layer of the gut, which is arranged in folds consisting of villi and crypts serving to increase the absorptive surface area. The epithelium consists of a single layer of absorptive columnar epithelial cells, goblet cells, and intraepithelial lymphocytes separated from the underlying lamina propria by the basal lamina, creating a well defined functional compartment which plays a major role in interpreting intraluminal events. ${ }^{5}$ The epithelium is constantly assaulted by antigens from a dietary and infective source and provides the first line of interaction with the immune system. The majority of intraepithelial $\mathrm{T}$ cells found in the epithelial cell layer have a suppressor/cytotoxic phenotype while the lamina propria cells below consist of helper/inducer $\mathrm{T}$ cells and B cells. ${ }^{56}$

The lamina propria contains a full complement of mononuclear cells including B cells, T cells, and cells of the monocyte-macrophage lineage. ${ }^{7}$ The $\mathrm{T}$ cells that are present primarily utilise the $\alpha \beta$ T cell receptor and are either CD4 (helper) or CD8 (suppressor/cytotoxic) with a ratio very similar to that of peripheral blood. The majority lamina propria CD4 lymphocyte $T$ cells possess an accessory phenotype associated with helper-inducer cells aiding in immunoglobulin production by B cells. ${ }^{8}$ The Peyer's patches found within the lamina propria are more accessible to micro-organisms than other epithelial surfaces of the gut containing specialised transport cells called M cells, ${ }^{9}$ which lack microvilli and are able to phagocytose both soluble antigens and micro-organisms. The lymphocytes in Peyer's patches are activated and disseminate via mesenteric lymph nodes, thoracic duct and the bloodstream back to the lamina propria. ${ }^{10}$

\section{Cell types}

Immune responses are mediated by leucocytes, which derive from precursors in the bone marrow. Leucocytes comprise polymorphonuclear leucocytes and macrophages of the innate immune system and the two major types of lymphocytes of the adaptive immune system. B lymphocytes mature in the bone marrow while $\mathrm{T}$ lymphocytes mature in the thymus. Mature macrophages migrate to the lamina propria while lymphocytes continually recirculate from the bloodstream through the gut GALT where antigen is trapped and presented in the Peyer's patches.

GALT comprises various cell types, which include leucocytes or white blood cells and is subcategorised as:

(1) Phagocytes which include neutrophils, monocytes and macrophages, which form part of the innate immune system and provide nonspecific immunity.

(2) Lymphocytes which mediate adaptive or specific immunity.

Macrophages play a part in natural innate immunity by phagocytosing and degrading antibody coated and complement opsonised foreign particles such as microbes and antigens, killing microbes by the secretion of enzymes, reactive oxygen radicals, and lipid derived mediators (fig 2). Macrophages are also the principal effector cells of cell mediated immunity secreting a host of cytokines and growth factors. ${ }^{11}$ As participants of a specific immune process, macrophages have on their surface receptors for various microbial constituents enabling display of foreign antigens on the cell surface which are recognised by antigen specific T lymphocytes. ${ }^{12}$ Macrophages also promote $\mathrm{T}$ cell activation by the production of cytokines. ${ }^{13}$ 


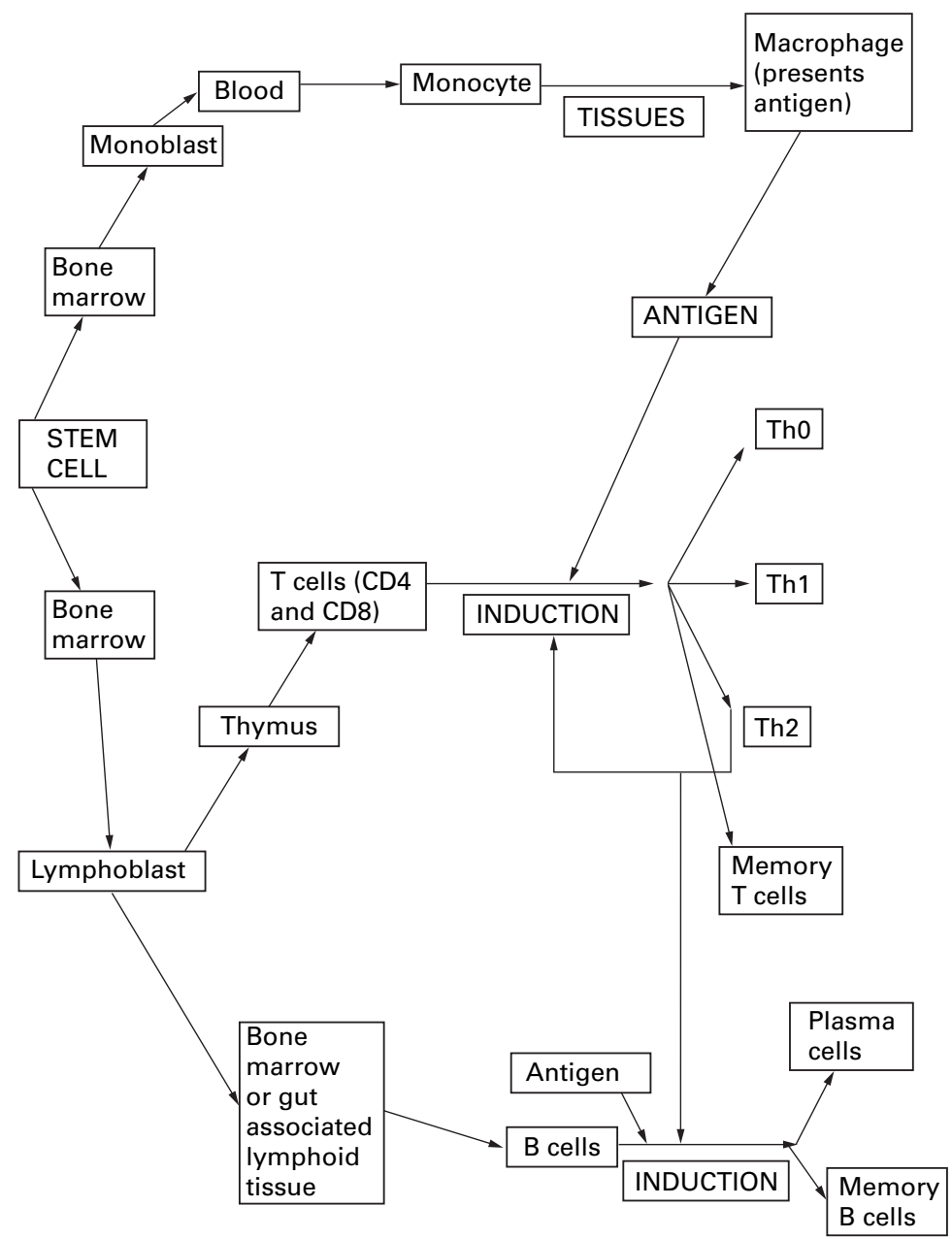

Figure 3 Cellular development of the immune response ( $T h=T$ helper $)$.

\section{PROINFLAMMATORY} Exotoxin, endotoxin Bile acids, digestive enzymes

IFN- $\gamma$, TNF- $\alpha$, IL-1
Pathogenic bacteria Dietary antigens

\section{PROTECTIVE}

Probiotic bacteria Mucus, slgA

$\mathrm{PGE}_{2}, \mathrm{PGI}_{2}$ IL-1 ra, IL-10, TGF- $\beta$

Short chain fatty acids

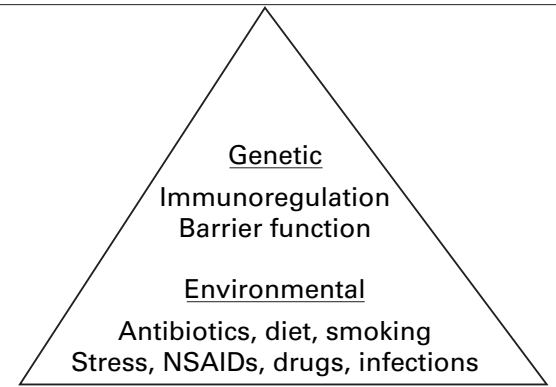

Figure 4 Balance of proinflammatory components and host protective forces in the gastrointestinal tract (for abbreviations see text).

The $\mathrm{T}$ cells are differentiated in the thymus into different subpopulations, the $\mathrm{T}$ helper or $\mathrm{T}$ cytotoxic/suppressor cells, with different markers to identify them; CD4+ for T helper and CD8+ for T cytotoxic or suppressor cells. $\mathrm{T}$ helper cells have three subtypes, Th1, Th2, and Th0 with distinct functions distinguished by the product of their secretions. ${ }^{14}$

The B cells are differentiated in the bone marrow and consist of two populations. The first characterised by the marker CD5+ is found in the peritoneal cavity and constitutes $15 \%$ of the total $\mathrm{B}$ cell population. The second type constitutes $85 \%$ of B cells and is found in the blood and all organs of the immune system (see fig 3).

There is a third population of non-B, non- $\mathrm{T}$ cells whose differentiation is uncertain.

This population also includes the killer $(\mathrm{K})$ and natural killer (NK) cells which have important functions in host defences against tumours. $^{15}$

\section{Secretory components}

The first line of defence against pathogenic bacteria is immune exclusion involving $\operatorname{IgA}$ antibodies. IgA secretion is usually induced in the Peyer's patches when B cells are stimulated. ${ }^{16}$ Committed $\mathrm{B}$ cells then migrate into the systemic circulation and into the lamina propria to produce $\operatorname{IgA} .{ }^{17}$ IgA acts in cooperation with non-immunological defence mechanisms to mediate immune exclusion of foreign antigens by preventing epithelial adherence and penetration of invasive pathogenic micro-organisms, neutralising toxins and viral multiplication.

The second line of defence involves the IgG antibodies and a large number of mediators which include the proinflammatory cytokines.

Recent studies have also suggested the presence of a novel form of innate immunity, which may be mediated in the lumen and at the mucosal surface, in the form of antimicrobial peptides. ${ }^{18}$ Members of three families of antimicrobial peptides - the defensins, magainins, and cecropins - have been isolated from the gastrointestinal tract of animals. ${ }^{19}$

\section{Cytokines}

The presentation of antigen in the inflammatory process is closely followed by generation of cytokines, which provide signals for the communication among different cell populations determining the direction of the subsequent immune and inflammatory response. Cytokines are small glycoprotein peptide molecules between 5 and $50 \mathrm{kDa}$ with autocrine, paracrine, and endocrine activites. ${ }^{20}$ Each may have several actions but may be broadly classed as proinflammatory or anti-inflammatory in nature. Proinflammatory cytokines include interleukin (IL)-1, IL-6, IL-8 and tumour necrosis factor-alpha (TNF- $\alpha$ ), although IL-1 also has a role in tissue healing and IL-6 in inducing the release of anti-inflammatory acute phase proteins. ${ }^{2122}$ IL-4, IL-10, and transforming growth factor-beta (TGF- $\beta$ ) are considered as anti-inflammatory cytokines (see fig 3). Macrophages are the major sources of cytokines, with epithelial cells also being able to produce a number of these peptide factors. ${ }^{23} \mathrm{~T}$ helper (Th) cells are a further important source of cytokines. Th1 cells, which are associated with a cell mediated immune response, produce IL-2, interferon gamma (IFN- $\gamma$ ) and TNF- $\alpha$. Th 2 cells enhance antibody synthesis by $\mathrm{B}$ cells and produce IL-4, IL-5, IL-6, and IL-10. There is evidence for the predominance of a Th1 or Th2 response in certain human 
diseases. ${ }^{24}$ TNF- $\alpha$ has an important and wide ranging role in the inflammatory response and in host resistance, with its ability to induce or suppress expression of a number of genes. ${ }^{25}$

The epithelial cell is the first host cell that interacts with luminal pathogenic microorganisms and initiates mucosal disease by secreting proinflammatory cytokines in response pathogens or their products. ${ }^{26}$ After epithelial injury, increased permeability results in activation of exposed lamina propria macrophages and lymphocytes. The cytokines produced by all three cell types are therefore important in directing the inflammatory process.

Destructive enzymes, oxygen radicals, and nitrogen metabolites

Intestinal macrophages also release proteases such as elastase, cathepsin G, and collagenase and other destructive lysosomal enzymes after stimulation by phagocytosis, lipopolysaccharide, or cytokines. The phagocytic leucocytes are also a major source of oxygen radicals and nitrogen metabolites such as $\mathrm{NO}_{2}{ }^{-} \cdot{ }^{27}{ }^{28}$ Phagocytic cells used reactive oxygen radicals in combination with proteases to destroy ingested micro-organisms. Oxygen radicals are potentially detrimental if not controlled causing lipid peroxidation and membrane destabilisation increasing mucosal permeability in the inflamed intestine. ${ }^{29}$

\section{Eicosanoids}

Eicosanoids are a group of 20 carbon fatty acids and peptidofatty acids derived from membrane phospholipids. ${ }^{30}$ Mostly, the eicosanoids are thought of as proinflammatory mediators, however some prostaglandins can exert potent anti-inflammatory effects under certain conditions. ${ }^{31}$

Prostaglandins have actions on vascular smooth muscle $\left(\mathrm{PGE}_{2}\right.$ and $\mathrm{PGI}_{2}$ relax: $\mathrm{PGF}_{2}-\alpha$ contracts), platelet aggregation ( $\mathrm{PGI}_{2}$ and $\mathrm{PGD}_{2}$ inhibit), neutrophil secretion, adherence, and motility ( $\mathrm{PGE}_{2}$ and $\mathrm{PGI}_{2}$ inhibit), and gastric acid secretion ( $\mathrm{PGI}_{2}$ and $\mathrm{PGE}_{2}$ inhibit). ${ }^{32}$ Prostaglandins also have been shown to exert protective effects in the stomach, small intestine, and colon, although the mechanism of action remains unclear. ${ }^{33}$

Thromboxane is a platelet derived substance with vasoconstrictor actions in many vascular beds with potent activity as a platelet aggregator. ${ }^{34}$ Leukotrienes can be divided into two subgroups. $\mathrm{LTB}_{4}$ is a potent stimulus of neutrophil secretion, aggregation, adherence, and migration. ${ }^{35}$ The peptidoleukotrienes $\left(\mathrm{LTC}_{4}, \mathrm{LTD}_{4}\right.$, and $\left.\mathrm{LTE}_{4}\right)$ exert potent constrictor effects on vascular and non-vascular smooth muscle. These leukotrienes are also capable of increasing vascular permeability and of stimulating adherence of leucocytes to the vascular endothelium. ${ }^{36}$ Eicosanoids also exert immunomodulatory effects with $\mathrm{PGE}_{2}$ suppressing the production of IL- 1 and TNF- $\alpha$ by monocytes and inhibitng various $\mathrm{T}$ lymphocyte functions. ${ }^{37} \mathrm{LTB}_{4}$ can also modify the proliferation of $\mathrm{B}$ lymphocytes and stimulate the production of TNF- $\alpha$, IFN- $\gamma$, IL-2 from mononuclear cells. ${ }^{38}$ These proinflammatory mediators are important as they are now the target of various therapeutic interventions (see fig 4).

\section{Inflammatory response}

\section{INITIATION}

An inflammatory response is mounted against an antigen from the gut lumen when it is transported by specialised epithelial $\mathrm{M}$ cells into the lymphoid follicles. Macrophages, dendritic cells, and B cells have surface receptors which recognise and bind the common constituents of many bacterial surfaces. ${ }^{39}$ Dendritic cells have a critical role in immunity to viruses while macrophages specialise in internalising and presenting particulate antigens. ${ }^{40}$ There is trapping, engulfment, and destruction of the pathogen by tissue macrophages providing an immediate innate cellular immune response.

\section{AMPLIFICATION}

This innate immune response recruits more phagocytic cells and effector molecules to the site of the infection through the release of cytokines. Cytokines produced by macrophages are called monokines (IL-1, IL-6, IL-8, IL-12, and TNF- $\alpha$ ). Other mediators released include prostaglandins, nitric oxide, leukotrienes, and platelet activating factor. In addition to this the effect of complement also contributes to the inflammation. ${ }^{41}{ }^{42}$ This whole process may be sufficient to prevent an infection from becoming established even after a microbe has crossed an epithelial barrier.

\section{Adaptive response}

The presentation of antigen also triggers an adaptive response, which begins through presentation of processed antigens in context with the major histocompatibility complex (MHC). This process leads to activation of $\mathrm{T}$ cells. ${ }^{43}$ Presentation of antigens in association with MHC class I molecules results in activation of CD8 positive $T$ cells, whereas presentation in association with MHC class II group molecules induces CD4 $\mathrm{T}$ cell activation. ${ }^{44}$ HLA class I molecules generally present cytoplasmic antigens (endogenous antigens) that are primarily synthesised by the infected cells-for example, viral proteins. Under normal physiological conditions antigen presentation by intestinal epithelial cells leads to stimulation of CD8 positive cells with suppressor function. These primed lymphocytes leave the mucosa, enter the circulation, and migrate back to mucosal surfaces; a process known as "homing" ${ }^{45}$ The defence systems of innate immunity are effective in combating a bacterial pathogens but are limited to those bacteria bearing common surface molecules. To overcome this, each naive lymphocyte entering the bloodstream bears receptors of only a single specificity. The specificity of each lymphocyte gives rise to millions of different specificities. These lymphocytes continually undergo natural selection during the life of the individual with only those encountering an antigen to which their receptor binds activating and differentiating into effector cells. ${ }^{46}$ 


\section{Resolution}

The outcome of an immune response is determined by the kind of effector cells which are stimulated by the initially activated $T$ cells. The result of this specific response is the activation of immune, mesenchymal, epithelial cells, recruitment of circulating effector cells, tissue damage, and/or healing. These mediators determining the resolution include cytokines, archidonic acid metabolites, reactive oxygen intermediates, and growth factors. Chronic inflammation of the intestine as found in the IBDs is thought to result from failure of these regulatory mechanisms that normally serve to limit the immune response and to eliminate a pathogen. ${ }^{47}$

\section{Regulation}

The net effects of cytokines play a large part in regulating the inflammatory response. The developmental pathway of $\mathrm{T}$ cells depend on cytokines present in their microenvironment. Exposure to IFN- $\gamma$ results in Th1 cells that produce IL- 2 and IFN- $\gamma$. IL- 4 drives development of Th2 cells and conversely IFN- $\gamma$ down regulates cytokine production by Th2 cells. The differentiation of $\mathrm{T}$ cells into Th1 or Th2 like cytokines is a process that itself is dependent on cytokines present in the microenvironment. ${ }^{47} 48$

Neuroendocrine hormones-for example, substance $\mathrm{P}$, have also been found in increased concentration in the mucosa of the inflamed bowel suggesting a further mechanism for enhancement of the mucosal inflammatory response. ${ }^{49}$

The differentiation of IgA producing B cells is also dependent on factors produced by lymphoid cells. TGF- $\beta$ increases IgA production by IgA negative, lipopolysaccharide stimulated B cells. ${ }^{50}$ Human IFN- $\gamma$ and IL-4 enhance the expresssion of secretory component on the HT-29 epithelial cell line suggesting that local production of cytokines may alter IgA transport. ${ }^{51}$

Oral challenge of the intestinal mucosal immune system often leads to systemic immune unresponsiveness to the administered antigen. This unresponsiveness or tolerance is mediated in part by antigen specific suppressor $\mathrm{T}$ cells that develop in the mucosal lymphoid follicles that migrate to other lymphoid tissues. $^{52}{ }^{53}$ Additional mechanisms of suppression at play include clonal deletion and anergy. ${ }^{54}$

\section{Effects on intestinal function}

The chronically inflamed gut brings about a distortion of structure in the form of mucosal ulceration, laying down of fibrous tissue, the space occupying effect of inflammatory cell infiltrates, and changes in the growth and maturation of cells in the epithelium and muscle layers resulting in muscle thickening and villous blunting

Continuous inflammation-for example, in IBD, is associated with changes in water and ion transport by epithelial cells contributing to diarrhoea. There is a net accumulation of fluid in the intestinal lumen leading to an frequency and volume of stools. Inflammation also leads to a loss of the normal surface area which is associated with loss of digestive enzymes, a decreased breakdown and absorption of food products, loss of the normal absorption of protein and fat, weight loss, and malnutrition. The integrity and permeability of the intestinal epithelial layer is disrupted during inflammation as in IBD resulting in increased serum antibody levels to food and milk proteins. ${ }^{55}$ Virtually every aspect of gut function is subject to modulation by the immune system. The function of cells anywhere in the gut wall may be altered by the presence of inflammation. Structural and physiological tissues may contribute to the inflammatory process by producing cytokines that chemoattract and facilitate the survival of immunological cells in the local environment, and that maintain a state of organ dysfunction by virtue of their effects on physiological systems both within and outside the gut. These processes have a bearing on many of the symptoms, including pain, diarrhoea, and weight loss that invariably accompany IBD.

\section{Therapeutic intervention: controlling excessive inappropriate inflammation} Reducing inflammation in IBD is based on immunomodulatory regimens. Two firmly established routes are through the use of corticosteroids and aminosalicylates (5-ASA). The therapeutic effects of steroids are mediated by inhibition of several inflammatory pathways, including direct suppression of the 5-lipoxygenase mediated metabolism of arachidonic acid, modulated transcription of glucocorticoid sensitive proteins, and suppression of mRNA for most of the interleukins. ${ }^{56}$ The mechanism of action of 5-ASA in reducing intestinal inflammation in IBD includes inhibition of 5-lipoxygenase metabolism and the production of interleukins and inflammatory leukotrienes; suppression of platelet activating factor, normalisation of intestinal permeability, chemotaxis of neutrophils and monocytes, reduction of epithelial HLA-DR expression; stimulation of cytoprotective prostaglandins; and scavenging of free radicals. ${ }^{57}$

Azathioprine, cyclosporin, and methotrexate are steroid sparing immunosuppressants used to control intestinal inflammation. Azathioprine is a purine analogue that competitively inhibits the biosynthesis of purine nucleotides resulting in selective suppressant effects on $\mathrm{T}$ cells. Cyclosporin acts primarily on $\mathrm{T}$ cell function and proliferation mainly by inhibition of IL-2 gene transcription. Methotrexate suppresses $\mathrm{T}$ cell function by decreasing folate dependent enzyme activity in lymphocytes.

\section{Novel drugs with specific} anti-inflammatory targets

The presence of raised proinflammatory mediators in IBD has led to the development of therapies targeted at key sites for promoting or interfering with processes involved in the regulation of the inflammatory cascade.

Antibodies against TNF- $\alpha$ have been raised in mice and genetically modified to make them less immunogenic. Two anti-TNF- $\alpha$ antibodies 


\section{Questions}

\section{(answers at end of paper)}

(1) What are the major proinflammatory initiators in the gastrintestinal tract?

(2) What factors are responsible for the regulation and suppression of gastrintestinal inflammation?

(3) What part does IgA play in intestinal inflammation?

(4) What are cytokines and how do they work?

(5) What genetic and environmental factors can influence gastrintestinal inflammation?

are currently undergoing evaluation in Crohn's disease. ${ }^{58} \quad$ Regulatory anti-inflamamatory cytokines-for example, IL-10 and IL-11, are also undergoing studies on patients with Crohn's disease. ${ }^{59}$ Antagonists to lipid derived mediators including leukotriene B4 and thromboxane are also effective in reducing inflammation. Reactive oxygen metabolite scavengers such as superoxide dismutase have also been used with variable efficacy in IBD but none have appeared in practice at this time. ${ }^{60}$

\section{Summary}

This review has outlined the major pathways of inflammation in the gastrointestinal tract. Understanding of the mechanisms of these pathways has resulted in the identification of many potential target sites for new therapies along the inflammatory cascade. Once more key processes in inflammation are understood, further modification of present therapies along with more novel treatments will result in safer and more effective control of the inflammatory process in the gastrointestinal tract.

1 Brandtzaeg P, Halstensen TS, Kett K, et al. Immunobiology and immunopathology of human gut mucosa: humoral immunity and intraepithelial lymphocytes. Gastroenterology 1989;97:1562-84.

2 Gibson GR, Macfarlane GT. Intestinal bacteria and disease. In: Gibson SAW, ed. Human health - the contribution of microorganisms. London: Springer-Verlag, 1994: 53-62.

3 Gionchetti P, Rizzello F, Venturi A, et al. Maintenance treatment of chronic pouchitis: a randomised placebo controlled, double-blind trial with a new protobiotic preparation. Gastroenterology 1998;114:A1959.

4 Kruis W, Schuetz E, Fric P, et al. Double blind comparison of an oral Escherichia coli preparation and mesalazine in maintaining remission of ulcerative colitis. Aliment Pharmacol Ther 1997;11:853-6.

5 Gibson PR. Ulcerative colitis: an epithelial disease? In: Gibson PR, guest ed. Ballieres Clinical Gastroenterology Interson PR, guest ed. Ballieres Clinical Gastr.
national Practise and Research 1997;11:1.

6 Mayer L. Intestinal epithelium: a new immunological barrier. In: Tytgat GNJ, Bartelsman JFWM, Van Deventer $\mathrm{SJH}$, eds. Inflammatory bowel diseases. Falk symposia 85. Dordrecht, Netherlands: Kluwer Academic Publishers, 1995.

7 James SP. Mucosal T cell function. Gastroenterol Clin North Am 1991;20:567-612.

8 Shaw S. Characterization of human leukocyte differentiation antigens. Immunol Today 1987;8:25.

9 Trier JS. Structure and function of intestinal $M$ cells. Gastroenterol Clin North Am 1991;20:531-47.

10 Kagnoff MF. Functional characteristics of Peyer's patch cells. III. Carrier priming of T cells by antigen feeding. $\mathcal{F}$ Exp Med 1975;142:1425-35.

11 Stout RD. Macrophage activation by $\mathrm{T}$ cells: cognate and non-cognate signals. Curr Opin Immunol 1993;5:398-403.

12 Razi-Wolf Z, Freeman GJ, Galvin F, et al. Expression and

2 Razi-Wolf $Z$, Freeman GJ, Galvin F, et al. Expression and
function of the murine B7 antigen, the major co-stimulatory function of the murine B7 antigen, the major co-stimulatory
molecule expressed by peritoneal exudate cells. Proc Natl molecule expressed by peritoneal
Acad Sci US A 1992;89:4210-14.
13 Arai K, Lee F, Mijajima A, et al. Cytokines: co-ordinators of immune and inflammatory responses. Annu Rev Biochem 1990;59:783.

14 Mosmann T, Coffman R. Two types of mouse helper T cell clone. Implications for immune regulation. Immunol Today 1987;8:223-33.

15 Osmond DG. The turnover of B-cell populations. Immunol Today 1993;14:34-7.

16 Reth M. B-cell antigen receptors. Curr Opin Immunol 1994; 6:3.

17 Hall J. Lymphocyte recirculation and the gut: the cellular basis of humoral immunity in the intestine. Blood Cells 1979;5:479-92.

18 Mahida YM, Rose F, Chan WC. Antimicrobial peptides in the gastrointestinal tract. Gut 1997;40:161-4

19 Schonwetter BS, Stolzenberg ED, Zasloff MA. Epithelial anitbiotics induced at sites of inflammation. Science 1995;267:1645-8.

20 Fiocchi C. Cytokines. In: MacDermott RP, Stenson W, eds. Inflammatory bowel disease. New York: Elsevier Publishing Company, 1992: 137-62.

21 Cominelli F, Dinarello CA. Interleukin-1 in the pathogenesis of and protection from inflammatory bowel disease. Biotherapy 1989;1:369-75.

22 Akira S, Hirano T, Taga T, et al. Biology of multifunctional cytokines: IL6 and related molecules. FASEB f 1990;4: $2860-7$.

23 Eckmann L, Kagnoff MF, Fierer J. Epithelial cells secrete the chemokine interleukin- 8 in response to bacterial entry. Infect Immun 1993;61:4569-74.

24 Mossmann TR, Coffman RL. Th1 1 and Th2 cells: different patterns of lymphokine secretion lead to different functional properties. Anпu Rev Immunol 1989;7:145-73.

25 Beutler B, Cerami A. The biology of cachetin/TNF. A primary mediator of the host response. Annu Rev Immunol primary mediator

26 Kagnoff MF, Eckmann L. Epithelial cells as sensors for microbial infection. $\mathcal{F}$ Clin Invest 1997;100:6-10.

27 Whittle BJR. Nitric oxide-mediator of inflammation or mucosal defence. Eur F Gastroenterol Hepatol 1997;9:102633.

28 Shanahan F, Targan S. Mechanisms of tissue injury in inflammatory bowel disease. In: MacDermott RP, Stenson WF, eds. Current topics in gastroenterology. Inflammatory bowel disease. New York: Elsevier, 1992: 77-93.

29 MacDermott RP, Stenson WF. Inflammatory bowel disease. In: Targan S, Shanahan F, eds. Immunology and immunopathology of the liver and the gastrointestinal tract. New York/Tokyo: Igaku-Shoin, 1990: 459-86.

30 Eberhart CE, Dubois RN: Eicosanoids and the gastrointestinal tract. Gastroenterology 1995;109:285-301.

31 Hawkey CJ, Rampton DS. Prostaglandins and the gastrointestinal mucosa: are they important in its function, disease intestinal mucosa: are they important in its function,

32 Wallace JL, Tigley AW. Review article: new insights into prostaglandins and mucosal defence. Aliment Pharmacol Ther 1995; $9 \cdot 227-35$.

33 Goodwin JS. Are prostaglandins proinflammatory, antiinflammatory, both or neither? f Rheumatol 1991;18 (suppl 28):26-9.

34 Davies GR, Rampton D. Eicosanoids: role in gastrointestinal inflammation and cancer. Eur $\mathcal{f}$ Gastroenterol Hepatol 1997;9:1033-45.

35 Sharon P, Stenson WF. Enhanced synthesis of leukotriene B4 by colonic mucosa in inflammatory bowel disease. Gastroenterology 1984;86:453-60.

36 Hawkey CJ, Mahida TR, Hawthorne AB. Therapeutic interventions in gastrointestinal disease based on an understanding of inflammatory mediators. Agents Actions 1992; 35(suppl 1):C22-6. 37 Wallace JL, Kenan CM. An orally active inhibitor of leukotriene synthesis accelerates healing

38 Yamaoka KA, Claesson HE, Rosen A. Leukotriene B4 enhances activation, proliferation, and differentiation of human B lymphocytes. F Immunol 1989;143:1996-2000.

39 Neefjes JJ, Mombourg F. Cell biology of antigen presentation. Curr Opin Immunol 1993;5:27-34

40 Klein J, Satta Y, Ohuigin C. The molecular descent of the major histocompatibility complex. Anпu Rev Immunol 1993; 11:269-95.

41 Bhakdi S, Tranum-Jensen J. Complement lysis: a hole is a hole. Immunol Today 1991;12:318-20.

42 Morgan BP. Effects of the membrane attack complex of complement on nucleated cells. Curr Top Microbiol Immunol $1992 ; 178: 115-40$.

43 Moller G, ed. Origin of major histocompatbility complex diversity. Immunol Rev 1995;143:2-292.

44 Germain RN. MHC dependent antigen processing and peptide presentation: providing ligands for $\mathrm{T}$ lymphocyte activation. Cell 1994;76:287-99.

45 Brandtzaeg P. Review article: homing of mucosal immune cells- a possible connection between intestinal and articular inflammation. Aliment Pharmacol Ther 1997;11(suppl 3):2439.

46 Butcher EC, Picker LJ. Lymphocyte homing and homeostasis. Science 1996;272:60-6.

47 James SP, Klapproth JM. Major pathways of mucosal immunity and inflammation: cell activation, cytokine production and role of bacterial factors. Aliment Pharmacol Ther 1996;10(suppl 2):1-10

48 Pallone F, Monteleone G. Regulatory cytokines in inflamPallone F, Monteleone G. Regulatory cytokines in inflam-
matory bowel disease. Aliment Pharmacol Ther 1996; 10(suppl 2):75-80 


\section{Answers}

(1) The initiators of gastrointestinal inflammation are the luminal contents of the bowel. These contain normal commensal bacteria, pathogenic bacteria-for example, salmonella, shigella, campylobacter, and enteropathogenic $E$ coli. Components of these pathogenic bacteria-for example, lipopolysaccharide and exotoxin, endotoxin and formylmethionine leucylphylalanine may further exacerbate inflammation. Other luminal components that may play a part include bile acids, digestive enzymes, and dietary antigens.

(2) It is now known that components of the commensal flora known as probiotic bacteria may be able to protect against inappropriate excessive gastrointestinal inflammation. Protection in the lumen also comes in the form of secretory IgA. In the lamina propria the major regulatory and immunosuppressive cytokines include IL-10, TGF- $\beta$, IL-1 receptor antagonist, and IL-4. Extraintestinal regulatory components may take the form of hormones-for example, vasoactive intestinal peptide.

(3) IgA acts with other non-immunological defences at the epithelial surface-for example, mucus to mediate immune exclusion of foreign antigens by preventing their adherence and penetration. It also neutralises toxins and reduces viral multiplication.

(4) Cytokines are small glycoprotein peptide molecules expressed by a number of cell lineages of the immune system. These molecules have regulatory properties enabling them to control initiation, amplification, perpetuation, suppression, and resolution of an inflammatory response. Based upon these abilities, various pharmacotherapeutic cytokine preparations are presently used (for example, anti-TNF- $\alpha$ antibody) for the control of gastrointestinal inflammation. Further preparations are also under development.

(5) Genetic factors involved in gastrointesinal inflammation include immunoregulation and barrier function. Genetic irregularities in these two areas results in the IBD - that is, ulcerative colitis and Crohn's disease. Known environmental factors that may influence gastrointestinal inflammation include the use of antibiotics, diet, smoking, stress, drugs-for example, non-steroidal anti-inflammatory preparations and gastrointestinal infections. Both genetic and environmental factors hold the key to unravelling the mechanisms of IBD as well as providing clues to novel therapeutic preparations.

49 Mantyh PW, Gates TS, Zimmerman RP, et al. Receptor binding sites for substance $\mathrm{P}$, but not substance $\mathrm{K}$ or neuromedin $\mathrm{K}$ are expressed in high concentrations by arterioles, venules and lymph nodules in surgical specimens obtained from patients with ulcerative colitis and Crohn's disese. Proc Natl Acad Sci U S A 1988;85:3235-9.

50 Lebman DA, Lee FD, Coffman RL. Mechanism for transforming growth factor beta and IL-2 enhancement of IfA expression in lipopolysaccharide stimulated $\mathrm{B}$ cell cultures. F Immunol 1990;144:952-9.

51 Phillips JO, Everson MP, Moldoveanu Z, et al. Synergistic effect of IL-4 and IFN gamma on the expression of polymeric Ig receptor (secretory component) and IgA binding by human epithelial cells. F Immunol 1990;145:1740-4. Strober W, Richman LK, Elson CO. The regulation of
gastrointestinal immune responses. Immunol Today 1981;2: 156-61

53 Mowat AM. The regulation of immune responses to dietary protein antigens. Immunol Today 1987;8:93-8.

54 Gautam SC, Battisto JR. Orally induced tolerance generates an efficiently acting suppressor $\mathrm{T}$ cell and an acceptor $\mathrm{T}$ cell that together regulate contact sensitivity. F Immunol 1985;135:2975-83.
55 Olaison G, Sjodahl R, Tagesson C. Abnormal intestinal permeability in Crohn's disease. A possible pathogenic factor. Scand F Gastroenterol 1990;25:321.

56 Fahey JV, Guyre PM, Munck A. Mechanisms of antiinflammatory actions of glucocorticoids. In: Weismann G, ed. Advances in inflammation research. Vol 2. New York: Raven, 1981: 21-51.

57 Greenfield SM, Punchard NA, Teare JP, et al. Review article: the mode of action of aminosalicylates in inflammatory bowel disease. Aliment Pharmacol Ther 1993;7:369-83.

58 Targan SR, Rutgeers P, Hanauer SB, et al. A multicenter trial of anti-tumour necrosis alpha antibody for treatment of patients with active Crohn's disease. Gastroenterology 1996; 110:A1026.

59 Van Deventer SJH, Elson CO, Fedorak RN, et al. Safety, tolerance, pharmacokinetics and pharcodynamics of recombinatn interleukin-10 in patients with steroid refractory Crohn's disease. Gastroenterology 1996;110:A1034.

60 Salim A. Role of oxygen derived free radical scavengers in the management of recurrent attacks of ulcerative colitis: a new approach. f Lab Clin Med 1992;119:710-17. 